possible - within a few days for light bleeding, or the same day for heavier bleeding - to see whether the fetus is still alive. If it is the woman may be reassured that she has only a one in 10 chance of subsequently losing the pregnancy. ${ }^{2}$ If the fetus is dead and there are retained products of conception she may be admitted electively for evacuation within a few days to allow calm, daytime surgery, although if the bleeding is heavy she should be admitted immediately. This reduces the risk of septic abortion and other complications compared with that associated with emergency surgery later. If there is doubt about viability in a pregnancy of only a few weeks' gestation scanning may be repeated a week or 10 days later before proceeding to evacuation if appropriate. When she firs presents we also check the woman's blood group and give anti-D immunoglobulin if she is $\mathrm{Rh}$ negative.

In general practice the woman's beliefs abou the bleeding must be considered. It is worth explaining that the bleeding comes from the mother, not the baby; that in over $95 \%$ of cases the outcome is determined before the bleeding starts (as shown by scanning on the first day of bleeding); and that the bleeding does not itself harm the baby. It is dreadful for a woman to wait and see because she may be unwilling to commit herself to the pregnancy if she thinks that she is likely to lose it. The fact that a scan showing a viable fetus means that she has a better chance of having a successfu pregnancy (nine out of 10) than she started the pregnancy with (four out of five) is reassuring A pregnancy full of anxiety can lead to an overanxious, overprotective approach lasting long into the baby's childhood.

It must be pointed out to the patient that there is no evidence at all that rest influences the outcome. Otherwise she may think that she is to blame if she cannot or does not rest and subsequently miscarries.

Finally, aftercare needs attention. The woman needs to know what to expect after evacuation of retained products of conception so that signs of retained products or infection are acted on early She and her partner should be encouraged to allow themselves time to recover emotionally from the loss. Many women lose their libido and their interest in trying again for a baby after a miscarriage and should know that this is a normal grief-defence reaction, which usually passes quite quickly. They should be invited to come back to talk about it if they are not getting over their loss in a couple of months.

R C H LYLE

Lower Clapton Health Centre,

London $\mathrm{E} 5$

列 1991;302:1141-3. (11 May.)

2 Drumm JE. The value of ultrasonography in the management of first trimester haemorrhage. In: Studd J, ed. Progress in obstetrics and gynaecology. Vol 1. London: ChurchillLivingstone, 1981:30-8.

\section{Prognosis of breast cancer associated with pregnancy}

SIR, - Minerva states that many women and some doctors continue to believe that breast cancer has a poor prognosis if it is diagnosed during pregnancy or within one year of delivery.' She then quotes an article from the Memorial Sloane-Kettering Cancer Center, New York, suggesting that cancers associated with pregnancy are no more or less aggressive than others. ${ }^{2}$ It should be recognised that this was a review of 56 patients, of whom only 12 were diagnosed and treated before delivery, and $80 \%$ of the 12 did not have spread to the lymph nodes. The numbers are small and the proportion of patients without spread to the lymph nodes surprisingly high.

In contrast, a series from the Princess Margaret
Hospital, Toronto, which included 154 patients whose tumours were coincident with pregnancy and 96 whose tumours arose during the 12 months after parturition (conventionally termed "the lactation period"), showed a serious reduction in survival for these patients. ${ }^{3}$ Patients whose tumours were coincident with pregnancy had a poor survival of $32 \%$ at five years and $25 \%$ at 10 . Relapse free survival was $24 \%$ at five years and a dismal $18 \%$ at 10 years. Patients whose tumours arose during the lactation period fared a little better, with a five year survival of $39 \%$ and a 10 year survival of $35 \%$. Among those whose tumours were coincident with pregnancy there was no difference in survival between patients with and without spread to the lymph nodes, and only $10 \%$ of these patients had tumours less than $2 \mathrm{~cm}$ in diameter.

The Sloane-Kettering series matched breast cancers that were associated with pregnancy with breast cancers that were not and were of the same stage and compared survival. This does not take into account, however, that patients with breast cancers associated with pregnancy have a strong tendency to present with more advanced disease, presumably because of the pregnancy itself. Such a comparison therefore becomes irrelevant as it is the effect of the pregnancy that is the dominant factor.

Ontario Cancer Institute

R M CLARK

argaret Hospital

Ontario,

Canada $M 4 X 1 K 9$

1 Minerva. Views. BMJ 1991;302:798. (30 March.)

2 Petrek JA, Dukoff R, Rogatko A. Prognosis of pregnancy associated breast cancer. Cancer 1991;67:869-72.

Clark RM, Chua T. Breast cancer and pregnancy: the ultimate challenge. Clinical Oncology 1989;1:11-8.

\section{Breast cancer screening: the current position}

SIR, - Dr J A Muir Gray and colleagues' refuse to accept the failure of the British randomised controlled trial of mammography and physical examination to show statistically sound evidence of benefit ${ }^{2}$ and accuse unbelievers of "inappropriate use of epidemiology." Their argument, however, is based on the inappropriate use of meta-analysis.

As shown by Professor Nicholas Wald and colleagues, ${ }^{3}$ three of the four randomised controlled trials of mammography failed to reach statistically significant benefit for women aged 50 and over.

Professor Wald and colleagues suggest that the reason for the failure to show a clear benefit in the Malmö and Edinburgh trials was that both were small studies. If studies of 16000 women in Malmö and 14000 women in Edinburgh who accepted screening and were followed up for 10 and seven years, respectively, are "small" then the clinical benefits of such screening, if any, must also be small. As Dr Muir Gray and colleagues rightly point out, "doctors need to know the clinical benefits of such screening and not to be confused by statistical red herrings.'

One of the red herrings is the combination of randomised controlled studies and case-control studies in an attempt to show the non-significant as significant. Gullberg et al showed that applying case-control methodology to their data from the Malmö randomised controlled trial "improved" the clinical benefit from a relative risk of 0.96 (not significant) to 0.42 (highly significant). ${ }^{4}$ Casecontrol studies should thus not be combined in meta-analyses with prospective randomised trials. Dr Muir Gray and colleagues do not attempt to correct their meta-analysis for such biases.

Dr Muir Gray and colleagues express the opinion that "on the basis of the experience obtained in the early days of the NHS screening programme ... the quality being achieved was adequate to ensure that this benefit was attainable across the country."
In stark contrast, the authors of the report on the Edinburgh trial concluded with the statement that if the defects encountered in their trial "were to persist we would be only spending resources recklessly and to little or no effect.".

PETR SKRABANEK JAMES MCCORMICK

Department of Community Health, Trinity College,

Dublin 2

1 Muir Gray JA, Vessey MP, Patnick J. Breast cancer screening: the current position. BMF 1991;302:1084. (4 May.)

Roberts MM, Alexander FE, Anderson TJ, Chetty U, Donnan PT, Forrest APM, et al. The Edinburgh trial of screening for breast cancer: mortality at seven years. Lancet 1990:335:241-6. Wald N, Frost $C$, Cuckle $\mathrm{H}$. Brest cancer screening: the current position. BMF 1991;302:845-6. (6 April.

position. BMf 1991;302:845-6. (6 April.)
ullberg B, Andersson I, Janzon L, Ranstam J. Screening mammography. Lancet 1991;337:244.

SIR, - Dr J A Muir Gray and colleagues have taken issue with the statement that there is no statistically sound evidence that breast screening has ever saved a life in the United Kingdom.' This is difficult to reconcile with the fact that the only trials of screening in this country have been reported as statistically non-significant. ${ }^{23}$ I suggest that it is an inappropriate use of epidemiology to discount these disappointing results by supporting unjustified meta-analyses of foreign trials which are, to a greater or lesser extent, unreliable or irrelevant, or both. For example, there is good evidence to suggest that the benefits indicated by case-control studies are partly ${ }^{2}$ or even totally factitious. Furthermore, the relevance of the more reliable randomised trials must be questioned - for example, there are several reasons why the results from the Swedish two counties study might not be reproduced here, ${ }^{5}$ not least of which are the far superior attendance rates in Sweden.

Moreover, Dr Muir Gray and colleagues seem to be selective in their criticism of epidemiological integrity. They cite uncritically an overview by Professor Nicholas Wald and colleagues," which $(a)$ claims to describe the current position without any acknowledgment of the detractions of screening; $(b)$ includes the breast cancer detection demonstration project, which, as its title admits, was no more than a demonstration project, on the same graph as the randomised trials; and $(c)$ claims that randomised trials somehow underestimate benefit because they eliminate selection bias by including non-attenders in the study group.

I do not believe it is acceptable to say that screening saves lives when so many different factors-such as attendance rates; the method and frequency of screening; and input from radiologists, surgeons, pathologists, and community physicians - all contribute to the success of any individual programme. The fact remains that two of the finest centres in the United Kingdom failed to produce a statistically sound reduction in mortality at seven years using annual clinical examination and biennial mammography, and we have embarked on a national programme of triennial mammography alone. I agree that the weight of evidence suggests that screening probably will save some lives (and we could fill the letters column with arguments over how many), but I fear that the number will not be enough to outweigh the damage to the women traumatised in the process or the opportunity costs of the scheme. My origina letter was a plea to keep screening in the age group that enjoys the maximum cost to benefit ratio, ${ }^{7}$ and I stand by it.

ANTHONY RODGERS

Southmead Hospital,

Bristol BS10 5NB

1 Muir Gray JA, Vessey MP, Patnick J. Breast cancer screening: the current position. BMf 1991;302:1084. (4 May.)

2 United Kingdom Trial of Early Detection of Breast Cancer Group. First results on mortality reduction in the UK trial of Group. First results on mortality reduction in the UK 3 Roberts MM, Alexander FE, Anderson TJ, Chetty U, Donnan 